\title{
Short communication: Repeated mammary tissue collections during lactation do not alter subsequent milk yield or composition
}

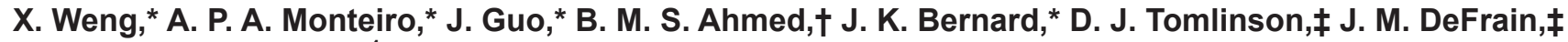 \\ G. E. Dahl,† and S. Tao*1 \\ *Department of Animal and Dairy Science, University of Georgia, Tifton 31793 \\ †Department of Animal Sciences, University of Florida, Gainesville 32611 \\ ‡Zinpro Corporation, Eden Prairie, MN 55344
}

\section{ABSTRACT}

Mammary biopsy collection (MB) is a valuable approach for studying mammary gland biology, but it is unclear if repeated $\mathrm{MB}$ impair the performance of lactating dairy cows. The objective of this trial was to examine the effect of repeated $\mathrm{MB}$ during lactation on udder health, dry matter intake (DMI), and lactation performance of lactating dairy cows. Sixty-four multiparous, mid-lactation Holstein cows were enrolled in a 29-wk trial, and 32 cows were randomly selected for repeated MB. The MB and non-MB (NMB) cows had similar parity $(2.6 \pm 0.9)$ and days in milk (96.5 \pm $56.3 \mathrm{~d})$ at enrollment. All animals were housed in the same barn and managed in the same manner. Cows were milked 3 times daily with milk yield recorded at each milking. Milk composition was measured weekly and DMI recorded daily. Three MB were performed per cow: 1 wk after enrollment and at 15 and 24 wk. The first and third MB were performed on the left rear quarter, whereas the second $\mathrm{MB}$ was on the right rear quarter. The MB were performed based on previously described procedures using a rotating stainless steel cannula with a retractable blade connected to a cordless drill, with appropriate sedation and antiseptic treatment after each MB. After MB, udder health, surgical wound healing, and presence of blood in milk were visually examined at each milking. Blood was cleared from milk $3.86 \pm 2.0 \mathrm{~d}$ after MB. During the experiment, 4 rear quarters of $\mathrm{MB}$ cows and 5 rear quarters from NMB cows were diagnosed and treated for clinical mastitis. No differences were observed in DMI, milk yield, somatic cell score, or milk concentration and yields of fat, protein, lactose, and solids-not-fat between $\mathrm{MB}$ and NMB. In conclusion, lactating cows recover rapidly from $\mathrm{MB}$, and repeated $\mathrm{MB}$ have no long-term effects on DMI, milk yield and composition, or udder health of lactating dairy cows.

Received March 19, 2017.

Accepted June 6, 2017.

${ }^{1}$ Corresponding author: stao@uga.edu
Key words: mammary biopsy, lactating cow, udder health, lactation performance

\section{Short Communication}

Studies that examine morphology and the functions of the bovine mammary gland require mammary tissue collected from animals either by sacrificing the animal or performing a mammary biopsy collection (MB). The advantage of the sacrificial procedure is that an enormous amount of tissue can be obtained from different quarters and locations within a quarter. However, this approach is economically expensive. On the other hand, MB is relatively inexpensive and a satisfactory amount of tissue can be extracted for histological and biochemical evaluations. Two common procedures for MB have been reported frequently in bovine studies. One uses a rotating cannula connected to a slow-speed electric motor by which a large tissue fragment (0.75 to $1 \mathrm{~g})$ can be collected (Farr et al., 1996). The other procedure uses core biopsy needles to extract small tissue fragments (20 to $25 \mathrm{mg}$ ) and may require several insertions to collect enough tissue for analysis (Soberon et al., 2010; Lima et al., 2016). Although MB is a valuable approach, concerns arise as to the potential for adverse effects of MB on udder health and performance of the cow. Within 1 wk after MB using a rotating cannula, intramammary blood accumulated during MB clears from the mammary gland and its function (yield and composition) recovers to the pre-MB level (Farr et al., 1996). It is not uncommon to perform multiple MB on the same animal to examine the effect of time or treatment by time. It has been reported that repeated MB using a biopsy needle (Lima et al., 2016) or a trocar coupled to a syringe (de Lima et al., 2016) transiently reduced milk yield after each MB. However, in most studies, the effect of repeated MB on cow performance was examined by comparing milk yield of the same cow before and after MB without any control animals included in the analyses, and the DMI data were not reported. Additionally, whether repeated MB using a rotating stainless steel cannula affects cow performance 
during lactation has never been reported. Thus, the objective of this study was to examine the effect of repeated MB using a rotating stainless steel cannula on DMI, milk yield and composition, and mammary health of lactating dairy cows over a 6 -mo period.

Data used in this study were extracted from an experiment described by Weng et al. (2016). The trial was conducted at the Dairy Research Center on the University of Georgia Tifton Campus from April to October 2015. Treatments and animal handling were approved by the University of Georgia Institutional Animal Care and Use Committee before beginning the trial. Sixtyfour multiparous mid-lactation Holstein cows were enrolled in the trial and randomly assigned to the MB group $(\mathrm{n}=32)$ or the non-MB group (NMB, $\mathrm{n}=32)$. Cows from both groups had similar parity $(\mathrm{MB}=2.5$ vs. $\mathrm{NMB}=2.8 ; \mathrm{SEM}=0.2, P=0.13)$ and $\mathrm{DIM}(\mathrm{MB}=$ 85.7 vs. $\mathrm{NMB}=107.3 ; \mathrm{SEM}=9.8, P=0.13)$ at enrollment. At the beginning of the trial, 1 animal in the MB group was excluded from the experiment due to ketosisrelated indigestion, and 2 cows from the NMB group were excluded because of either lameness or refusal to eat behind a Calan gate. The data from these 3 cows were not included in the analyses. Further, 1 NMB cow developed toxic mastitis during the second week of the trial and was excluded from the experiment. Due to the short period on the trial for this animal (1 wk), DMI and lactation performance data of this animal were not included in the analyses but the incidence of mastitis was reported.

Cows were housed in a 4-row freestall barn for $29 \mathrm{wk}$ and managed similarly during the experimental period. The MB were performed at wk 2, 15, and 24 of the trial. The first and third MB were performed on the left rear quarter, whereas the second $\mathrm{MB}$ was performed on the right rear quarter. Cows were milked 3 times daily $(0800,1600$, and $2400 \mathrm{~h})$ and milk yield was recorded at each milking (ALPRO Herd Management, DeLaval, Tumba, Sweden) throughout the trial. Milk samples were collected weekly from 3 consecutive milkings for SCC and composition analysis (fat, protein, lactose, SNF; Dairy One, Ithaca, NY). Somatic cell linear score (SCS) was calculated based on the equation SCS = $\log _{10}(\mathrm{SCC} / 12.5) / \log _{10} 2$. Cows were fed ad libitum and DMI was recorded daily for individual cows using the Calan gate system (American Calan, Northwood, NH) during the first $25 \mathrm{wk}$ of the trial. Milk yield and composition during the following week of each $\mathrm{MB}$ were not recorded because milk was discarded due to blood contamination.

The procedure for MB was based on the method reported by Farr et al. (1996). All animals were examined with no signs of clinical mastitis before each MB. Cows were sedated by intravenous injection of xylazine hydrochloride $(20 \mu \mathrm{g} / \mathrm{kg}$ of BW, AnaSed, Lloyd Laboratories, Shenandoah, IA) before each MB. The biopsied region in the midpoint of the quarter was shaved and sanitized 3 times by scrubbing with iodine followed by $70 \%$ ethanol. Local anesthesia was achieved with subcutaneous injection of $3 \mathrm{~mL}$ of $2 \%$ lidocaine hydrochloride (Animal Rx Pharmacy, Atlanta, GA) above the biopsy site. A 2- to 3-cm incision was made through skin and connective tissue, avoiding apparent blood vessels. A core of mammary tissue was obtained using a rotating stainless steel cannula with a retractable blade connected to a cordless drill (Farr et al., 1996). Incisions were then closed using 18-mm stainless steel Michel wound-clips (GerMedUSA, Garden City Park, NY) followed by topical administration of an aerosol bandage (Neogen Corp., Lexington, KY) to prevent infection. After MB, cows were kept in a small rubber-floored pen for 30 to $60 \mathrm{~min}$ to ensure there was no visible bleeding before cows returned to the freestall. After each MB, the quarter that was subjected to MB was hand-stripped before each milking to remove intramammary blood clots. Incision healing and presence of blood in milk were visually assessed at each milking. The occurrence of clinical mastitis was monitored by examining the milk for presence of visible flakes during forestripping at each milking.

The UNIVARIATE procedure of SAS (version 9.4; SAS Institute Inc., Cary, NC) was used to calculate the time elapsed after MB until blood was cleared from milk and wound clips were removed from the incision site; means \pm standard deviations are reported. The GLM procedure of SAS was used to analyze parity and DIM. The MIXED procedure of SAS 9.4 was used to analyze the repeated-measures data, including DMI, milk yield, and milk composition. The statistical model included fixed effects of treatment, time, and their interaction, with cow nested in the treatment as the random effect. For milk yield analysis, the average daily milk yield before onset of the experiment was included in the SAS model as a covariate. Data are reported as least squares means \pm standard error of the mean. Significance and tendency were declared when $P \leq 0.05$ and $0.05<P \leq$ 0.10 , respectively.

A core $(\sim 70 \times 4 \mathrm{~mm})$ of mammary tissue weighing $\sim 0.75 \mathrm{~g}$ was obtained in the current trial. In contrast to the small tissue fragments collected using biopsy needles (Lima et al., 2016), the amount of tissue collected by rotating cannula is sufficient for most histological and biochemical studies (Miller et al., 2006; Annen et al., 2007). Only one attempt was performed during each $\mathrm{MB}$ and the entire procedure lasted less than $30 \mathrm{~min}$. Although apparent large vessels were avoided, external bleeding was not completely eliminated in the present study. In contrast, external hemorrhage is minimized 
in MB using biopsy needles (Lima et al., 2016). In the current study, blood was cleared from milk at $3.9 \pm$ $2.0 \mathrm{~d}$ (mean $\pm \mathrm{SD}$ ) after MB, consistent with previous studies using rotating cannula (Farr et al., 1996) or biopsy needle (Lima et al., 2016), and wound clips were removed at $4.6 \pm 1.0 \mathrm{~d}$ after MB (Table 1), indicating rapid incision healing and recovery of mammary function. Further, we detected an effect of MB sequence $(P$ $<0.01)$ on the time when blood was cleared from milk; it took longer for the mammary gland to clear blood following the first $\mathrm{MB}$ compared with the subsequent MB [3.7 vs. 2.5 vs. 2.3 d (LSM) for the first, second, and third MB, respectively, SEM $=0.6 \mathrm{~d}$ ]. These data may reflect the experience of the technician in removing intramammary blood clots during the hand-stripping before milking. Throughout the trial, $4(6.5 \%)$ and $5(8.3 \%)$ cases of mastitis were identified in rear quarters of MB and NMB cows (Table 1), respectively, with no recurrence of mastitis in the same quarter of the same cow, indicating that MB had no influence on mammary health. A higher incidence of mastitis (12\%) was reported by Lima et al. (2016), but no occurrence of mastitis was observed by Farr et al. (1996) or Annen et al. (2007) after MB. The inconsistent results of mastitis occurrence after MB in different studies may be due to different stages of lactation of experimental animals, various lengths of experiments, the application of antibiotics following MB (Farr et al., 1996; Annen et al., 2007), different housing and milking management, distinct $\mathrm{MB}$ methods, or a combination of all. Regardless, data from the current study indicated that a low mastitis incidence following $\mathrm{MB}$ can be achieved through good management, even without the application of antibiotics.

No treatment effect or treatment by time interaction was observed $(P \geq 0.49)$ in DMI between MB and NMB cows ( 25.3 vs. $25.7 \mathrm{~kg} / \mathrm{d}, \mathrm{SEM}=1.2 \mathrm{~kg} / \mathrm{d}$; Figure 1$)$, suggesting no apparent systemic influence of repeated $\mathrm{MB}$ on the cows. Further, we observed no difference $(P=0.63)$ in milk yield between the groups $(\mathrm{MB}=$ 35.8 vs. $\mathrm{NMB}=35.2 \mathrm{~kg} / \mathrm{d}, \mathrm{SEM}=1.7 \mathrm{~kg} / \mathrm{d}$; Figure 2) throughout the trial, indicating that repeated MB had no long-term effect on milk yield of lactating Holstein cows. One limitation of the current study was that the short-term (within $1 \mathrm{wk}$ ) effect of $\mathrm{MB}$ on milk yield was not examined. To ensure consistent milking time and procedure, all cows were milked at the same time in the same milking parlor during the entire experiment. The milk was collected into a bucket during the week following $\mathrm{MB}$ and subsequently dumped to avoid blood contamination in the main milk line, and hence the milk yield was not recorded. In the study using biopsy needles, Lima et al. (2016) reported that milk yield was reduced only on the day following MB. In contrast, using a MB procedure similar to the one used in the current experiment, Farr et al. (1996) reported that milk yield was significantly reduced after tissue collection but recovered to the pre-MB level within $6.5 \mathrm{~d}$ post-MB. The short-term reduction in milk yield may be due to the trauma and stress caused by MB; however, milk yield fully recovers within $1 \mathrm{wk}$ as shown in the current study. The cellular mechanisms of the rapid recovery of milk yield after $\mathrm{MB}$ is unknown. The lactating mammary gland experiences compensatory growth in response to various stimuli (Knight and Peaker, 1982; Capuco and Akers, 1990); therefore, it is possible that, in the current study, the mammary gland also experienced a compensatory growth due to the loss of secretory tissue. However, it is unclear whether the compensatory growth occurred within the MB quarter or the non-MB quarters. Further research needs to be conducted to evaluate the milk yield response on individual quarters after MB. Moreover, in the current study, MB were performed in alternating rear quarters at an extended interval. In practice, subsequent $\mathrm{MB}$ may be performed on the same quarter at a shorter interval (i.e., 1 or 2 wk); therefore, additional research is required to further examine the effect of repeated $\mathrm{MB}$ on the same quarter with a shorter interval on milk production and mammary health on a single-quarter level and the whole-animal level.

Repeated MB had no long-term effect on SCS and concentration or yield of milk fat, protein, lactose, and SNF $(P \geq 0.11$; Table 1$)$, consistent with Farr et al. (1996). Similar to milk yield, the short-term effect of $\mathrm{MB}$ on milk composition was not evaluated in the current study. Previous MB research (Farr et al., 1996) in

Table 1. Incidence of mastitis, time for blood clearance in milk and removal of wound clips, and milk composition for cows subjected to repeated mammary biopsy collection $(\mathrm{MB}, \mathrm{n}=31)$ or not $(\mathrm{NMB}, \mathrm{n}$ $=30)$

\begin{tabular}{|c|c|c|c|c|}
\hline Parameter & MB & NMB & SEM & $P$-value \\
\hline Mastitis $^{1}$ & 4 & 5 & - & - \\
\hline Blood clearance, ${ }^{2} \mathrm{~d}$ & 3.9 & - & $2.0^{3}$ & - \\
\hline Wound clip removal, ${ }^{2} \mathrm{~d}$ & 4.6 & - & $1.0^{3}$ & - \\
\hline \multicolumn{5}{|l|}{ Milk composition } \\
\hline Fat, $\%$ & 3.32 & 3.34 & 0.09 & 0.56 \\
\hline Fat, kg/d & 1.23 & 1.24 & 0.08 & 0.93 \\
\hline Protein, \% & 2.69 & 2.77 & 0.03 & 0.11 \\
\hline Protein, kg/d & 1.00 & 1.00 & 0.07 & 0.78 \\
\hline Lactose, $\%$ & 4.67 & 4.66 & 0.03 & 0.75 \\
\hline Lactose, $\mathrm{kg} / \mathrm{d}$ & 1.75 & 1.72 & 0.16 & 0.60 \\
\hline SNF, $\%$ & 8.02 & 8.08 & 0.05 & 0.34 \\
\hline $\mathrm{SNF}, \mathrm{kg} / \mathrm{d}$ & 2.97 & 2.95 & 0.31 & 0.83 \\
\hline $\mathrm{SCS}^{4}$ & 2.85 & 3.17 & 0.35 & 0.34 \\
\hline
\end{tabular}

${ }^{1}$ Number of mastitis incidences in rear quarters of MB or NMB cows during the trial.

${ }^{2}$ Days after MB.

${ }^{3}$ Standard deviation.

${ }^{4} \mathrm{SCC}$ linear score $(\mathrm{SCS})=\log _{10}(\mathrm{SCC} / 12.5) / \log _{10} 2$. 


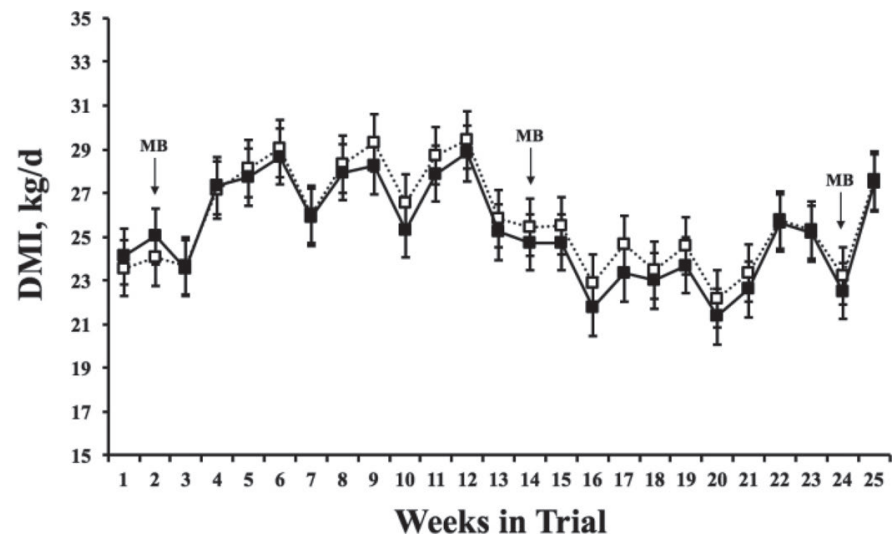

Figure 1. The DMI of lactating cows subjected to repeated mammary biopsy $(\mathrm{MB})$ collection $(\mathrm{n}=31$; solid squares, $\mathbf{\square})$ or not $(\mathrm{n}=30$; open squares, $\square)$. No treatment $(P=0.49)$ or treatment by time $(P=$ $0.79)$ effects were observed. Error bars represent SEM.

mid-lactation cows indicated an immediate but transient decrease in concentration of milk lactose due to leakage of lactose from the mammary gland into the circulatory blood system, resulting from breakage of the blood-milk barrier. In contrast, in early lactating cows, Lima et al. (2016) observed increased milk lactose concentrations but a decrease in milk protein concentration following $\mathrm{MB}$; however, those data were confounded with dramatic changes in milk composition during early lactation (Linn, 1988; Tsioulpas et al., 2007). Regardless of the approaches used, milk SCC transiently increase after MB in dairy cattle (Farr et al., 1996; Lima et al., 2016), indicating a possible inflammatory response due to trauma caused by MB. Data from the current study suggested that milk SCC returned to normal levels within 1 wk after MB. The

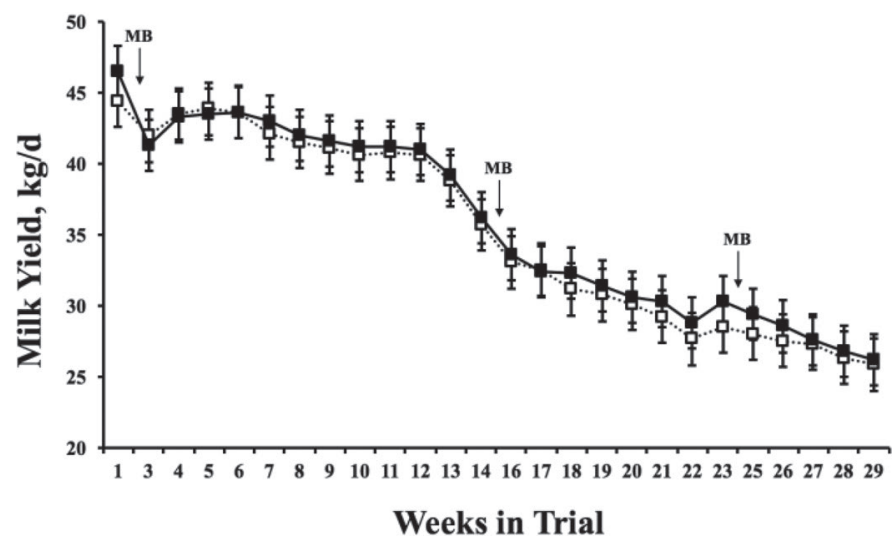

Figure 2. Milk yield of lactating cows subjected to repeated mammary biopsy (MB) collection $(\mathrm{n}=31$; solid squares, $\mathbf{\square})$ or not $(\mathrm{n}=30$; open squares, $\square)$. No treatment $(P=0.63)$ effect was observed, but there was a tendency for a treatment by time interaction $(P=0.06)$. However, the PDIFF and SLICE functions of SAS indicated time effects within each treatment rather than treatment effects at individual time points. Error bars represent SEM. change in milk SCS is consistent with cases of mastitis between MB and NMB cows, and further confirms that repeated $\mathrm{MB}$ using a rotating stainless steel cannula has no negative long-term effect on milk quality and mammary health.

In conclusion, although external hemorrhage occurred during $\mathrm{MB}$, blood was cleared from milk within a short period. The mammary gland recovered rapidly after $\mathrm{MB}$, and we found no evidence that MB impaired milk yield and composition, milk quality, or mammary health. Overall, repeated MB using a rotating stainless steel cannula had no effect on performance of lactating dairy cows.

\section{ACKNOWLEDGMENTS}

The authors thank the staff of the Dairy Research Center of the University of Georgia (Tifton, GA) for animal care and data collection. This project was supported by Zinpro Corporation (Eden Prairie, MN).

\section{REFERENCES}

Annen, E. L., A. C. Fitzgerald, P. C. Gentry, M. A. McGuire, A. V. Capuco, L. H. Baumgard, and R. J. Collier. 2007. Effect of continuous milking and bovine somatotropin supplementation on mammary epithelial cell turnover. J. Dairy Sci. 90:165-183.

Capuco, A. V., and R. M. Akers. 1990. Thymidine incorporation by lactating mammary epithelium during compensatory mammary growth in beef cattle. J. Dairy Sci. 73:3094-3103.

de Lima, L. S., E. Martineau, F. E. De Marchi, M. F. Palin, G. T. Dos Santos, and H. V. Petit. 2016. A new technique for repeated biopsies of the mammary gland in dairy cows allotted to Latin-square design studies. Can. J. Vet. Res. 80:225-229.

Farr, V. C., K. Stelwagen, L. R. Cate, A. J. Molenaar, T. B. McFadden, and S. R. Davis. 1996. An improved method for the routine biopsy of bovine mammary tissue. J. Dairy Sci. 79:543-549.

Knight, C. H., and M. Peaker. 1982. Compensatory increases in milk yield after hemimastectomy in lactating goats. Proc. Phys. Soc. $6: 36$.

Lima, J. A., J. R. Ruas, A. C. Vasconcelos, B. F. Silper, A. M. Lana, V. A. Gheller, H. M. Saturnino, R. B. Reis, and S. G. Coelho. 2016. Effects of bovine mammary gland biopsy and increased milking frequency on post-procedure udder health, histology, and milk yield. Animal 10:838-846.

Linn, J. G. 1988. Factors affecting the composition of milk from dairy cows. Pages 224-241 in Designing Foods: Animal Product Options in the Marketplace. National Research Council Committee on Technological Options to Improve the Nutritional Attributes of Animal Products. Natl. Acad. Press, Washington, DC.

Miller, N., L. Delbecchi, D. Petitclerc, G. F. Wagner, B. G. Talbot, and P. Lacasse. 2006. Effect of stage of lactation and parity on mammary gland cell renewal. J. Dairy Sci. 89:4669-4677.

Soberon, F., J. L. Lukas, M. E. Van Amburgh, A. V. Capuco, D. M. Galton, and T. R. Overton. 2010. Effects of increased milking frequency on metabolism and mammary cell proliferation in Holstein dairy cows. J. Dairy Sci. 93:565-573.

Tsioulpas, A., A. S. Grandison, and M. J. Lewis. 2007. Changes in physical properties of bovine milk from the colostrum period to early lactation. J. Dairy Sci. 90:5012-5017.

Weng, X., A. P. A. Monteiro, J. Guo, J. K. Bernard, J. M. DeFrain, and S. Tao. 2016. Effects of heat stress and dietary zinc source on mammary tight junction of lactating dairy cows. J. Anim. Sci. 94(Suppl. 5):344. (Abstr.) 